\title{
T Cell Antigen Receptor Vaccines for Active Therapy of T Cell Malignancies
}

\author{
SUNIL A. REDDY,${ }^{a}$ CRAIG OKADA,${ }^{b}$ CARMEN WONG,${ }^{c}$ DAVID BAHLER,${ }^{d}$ \\ AND RONALD LEVY ${ }^{a}$ \\ ${ }^{a}$ Stanford University Medical Center, Stanford, California 94305, USA \\ ${ }^{b}$ University of Michigan Medical Center, Ann Arbor, Michigan 48104, USA \\ ${ }^{c}$ Duke University, Durham, North Carolina 27710, USA \\ ${ }^{d}$ University of Pittsburgh Medical Center, Pittsburgh, Pennsylvania, USA
}

\begin{abstract}
T cell lymphoproliferative disorders continue to be serious management problems, and so alternative therapeutic modalities are continuously being explored. One such strategy involves immunotherapy using the $T$ cell receptor (TCR) as a target. Specifically we are attempting to develop a $T$ cell receptor idiotype (TCR-Id) vaccine because the TCR-Id can serve as a tumorspecific antigen. In this article we will briefly review the rationale for TCR-Id vaccines, the preclinical models as developed in our laboratory, and a discussion of our current plans for a vaccine trial in mycosis fungoides.
\end{abstract}

KEYWORDS: idiotype; $\mathbf{T}$ cell receptor; vaccine; $\mathbf{T}$ cell malignancies; mycosis fungoides; tumor antigens

\section{INTRODUCTION}

T cell lymphoproliferative disorders continue to be a serious management problem. Since only a fraction of patients are cured by standard treatment (radiotherapy and/or chemotherapy), alternative therapeutic modalities are constantly being explored. One such strategy involves immunotherapy using the T cell receptor (TCR) as a target. Specifically we are attempting to develop a $\mathrm{T}$ cell receptor idiotype (TCR-Id) ${ }^{1-4}$ vaccine because the TCR-Id can serve as a tumor-specific antigen. The idiotype is a collection of unique determinants found in the hypervariable regions of antigen receptors.

In this article we plan to briefly review the general rationale for TCR-Id vaccines, the preclinical models as developed in our laboratory, and a discussion of our current plans for a vaccine trial in a specific $\mathrm{T}$ cell malignancy known as mycosis fungoides (MF). ${ }^{5-7}$

Address for correspondence: Dr. Ronald Levy, Stanford University Medical Center CCSR North Wing, 1110, 269 Campus Drive, Stanford, CA 94305. Voice: 650-725-6452; fax: 650-7251420 . 


\section{MYCOSIS FUNGOIDES/CUTANEOUS T CELL LYMPHOMA}

There are a variety of $\mathrm{T}$ cell tumors (nodal and cutaneous $\mathrm{T}$ cell lymphomas and the T cell leukemias) that could serve as the subject of a TCR-Id vaccine trial. We have chosen a particular cutaneous T cell lymphoma (CTCL) known as mycosis fungoides for our planned vaccine trial.

MF is a prototypical $\mathrm{T}$ cell malignancy for development of vaccine therapy since it is the most common of the CTCLs with easy accessibility of tumor tissue by skin or lymph node biopsy. Also, MF has a well-defined natural history with high initial response rates to conventional therapies but with frequent relapses. ${ }^{5-7}$ There are no reliable alternative therapies for patients with recalcitrant or advanced disease. Patients with generalized thick plaque and/or tumor disease (stage IB-IIB) and patients with regional lymph node disease (stage IVA) are potential candidates to consider for vaccine therapy.

\section{RATIONALE FOR VACCINE THERAPY AGAINST THE TUMOR-SPECIFIC T CELL RECEPTOR}

The antigen receptors of T (TCRs) and B (immunoglobulin) cells are unique molecular targets because the formation of their variable regions requires the recombination of multiple $\mathrm{V}$, (D), and $\mathrm{J}$ germline segments. ${ }^{8}$ The final antigen receptor is further modified from the germline through the addition and deletion of junctional nucleotides in a template-independent manner. In the case of B cells, immunoglobulin can be further modified by somatic mutation. The variable region of the final product contains a unique sequence known as the CDR 3 region.

Most malignancies of $\mathrm{B}$ and $\mathrm{T}$ lymphocytes represent the transformation and expansion of a single clone, all of which have the same antigen receptor. Therefore, the $\mathrm{T}$ cell receptor of the malignant tumor clone could serve as a unique tumor-specific target.

We and others have had extensive experience in testing this hypothesis. Numerous studies have exploited the idiotype on B cell malignancies as a target for therapy in animal models and in human patients. ${ }^{9-22}$ Passive therapy with monoclonal antibodies against the tumor idiotype has resulted in a high frequency of, and occasional long-term regression of, B cell lymphomas in humans. ${ }^{23}$ Active vaccination with tumor idiotype proteins has led to immune responses in patients against their own $\mathrm{B}$ cell tumors. These responses have been associated with an improved clinical outcome. $^{12}$

There are several differences between the antigen receptors on T cells (TCRs) and $\mathrm{B}$ cells (BCRs) that predict that the TCR would provide an even better target for therapy. In contrast to the BCRs, the TCR does not undergo somatic mutation. ${ }^{24}$ This makes it much less likely that $\mathrm{T}$ cell tumors would escape from immunotherapy directed against their receptor. Unlike the BCR, there is no secreted form of the TCR, and therefore there is no decoy receptor in the serum of tumor-bearing subjects. Finally, there is evidence that ligands for the TCR have a direct antiproliferative effect on $\mathrm{T}$ cell tumors. 25 


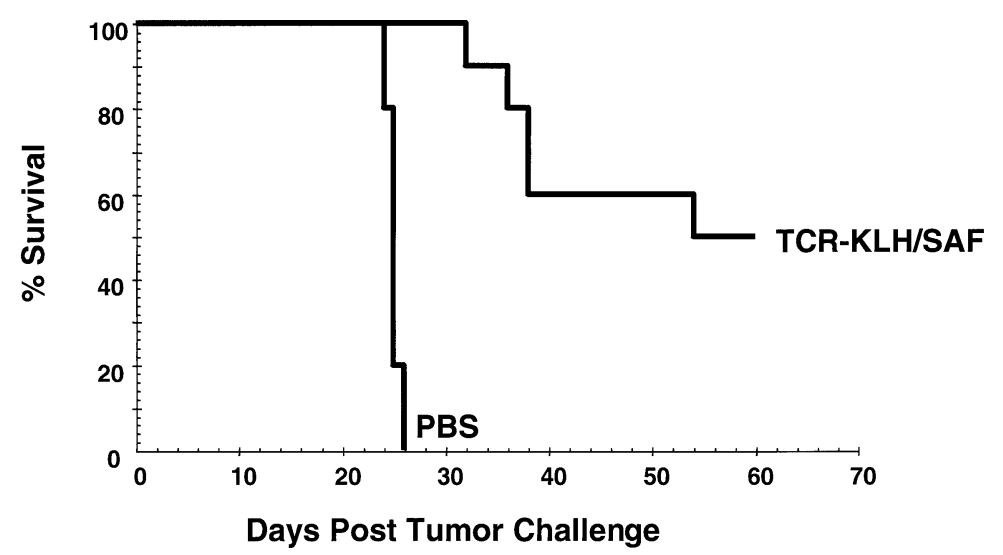

FIGURE 1. TCR vaccines protect mice against C6VL. Tumor challenge protection requires KLH and SAF. PBS, phosphate-buffered saline; SAF, Syntax adjuvant formulation.

\section{ANIMAL MODELS OF TCR-ID VACCINATION}

\section{Protein Vaccination}

Passive immunotherapy with V $\beta 8.2$ - (the $\beta$ chain of the disease-causing $T$ cell clone) specific antibody in a mouse autoimmune disease model (EAE-multiple sclerosis) prevented development of, and suppressed ongoing, disease. ${ }^{26-29}$ In this model, vaccination with this $\beta$ chain also showed protection. ${ }^{30-33}$ Passive TCR-Id antibody therapy has also been shown to be effective in T cell malignancy, in both a mouse model and a human patient. ${ }^{34,35}$

Based on the above rationale, we developed a TCR-Id protein vaccine in the mouse C6VL thymoma model. It required extensive effort to produce enough tumorspecific TCR protein for vaccination. The problem was overcome by developing a mammalian expression vector encoding both the $\alpha$ and $\beta$ chain of the TCR linked to a membrane-anchoring region of the decay accelerating factor (DAF, a phosphatidyl inositol-linked surface molecule). ${ }^{36}$ After selecting for cells with a high level of TCR expression, the protein could be released from the membrane by a specific phospholipase enzyme.

When mice were vaccinated with TCR protein linked to KLH (carrier protein) and mixed with Syntax adjuvant formulation (SAF), they were protected from challenge with the tumor (FIG. 1). ${ }^{1,2}$ Strong antibody responses to the specific TCR were generated. However, the evidence suggests that a CD8 T cell response is the mode of protective immunity. Depletion of CD8 T cells in the vaccinated mice abrogated the protective response. Protection against tumor challenge in this model system required both coupling of the TCR to the KLH carrier protein and the use of an immunologic adjuvant. 


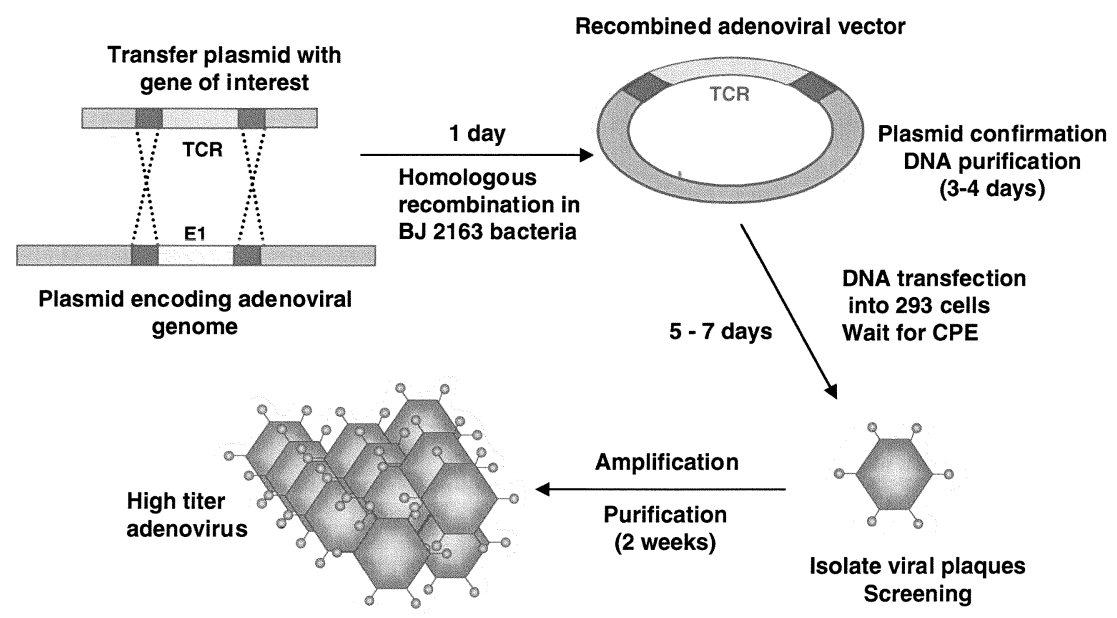

FIGURE 2. Production of recombinant adenovirus.

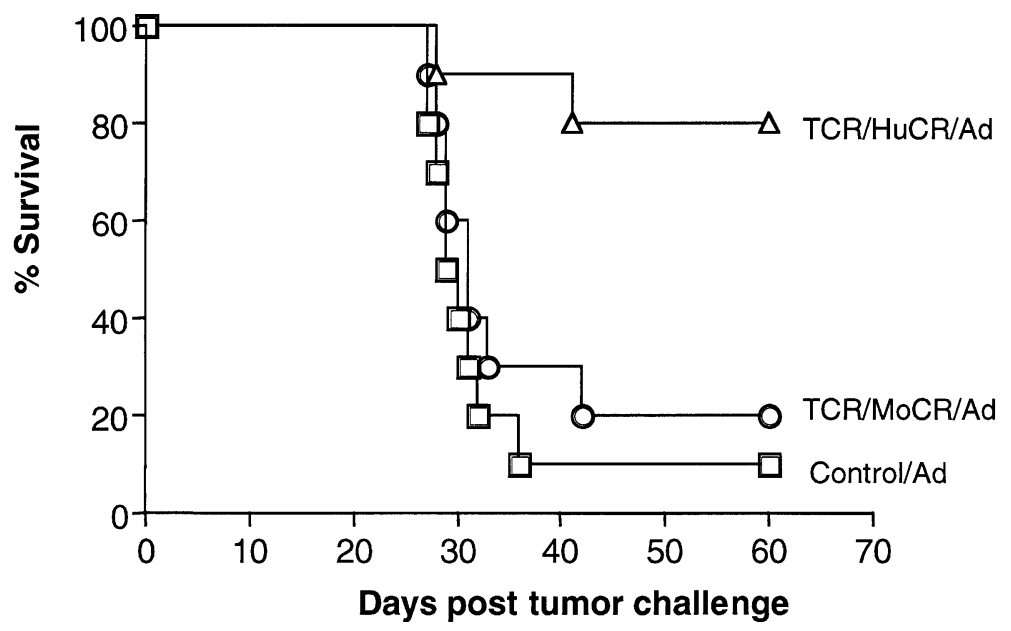

FIGURE 3. Protection against C6VL in mice vaccinated with TCR/HuCR/Ad. Tumor challenge with adenoviral vaccine requires human constant region. (Reprinted by permission from Wong \& Levy. ${ }^{3}$ )

\section{Adenovirus Vaccination}

The difficulty of making TCR protein for vaccination makes the approach currently inapplicable on a wide scale, as would be necessary for human trials.

We then explored the merit of TCR-Id encoding adenovirus for use in this vaccination model. This involved recombination between a plasmid encoding the TCR genes and a plasmid encoding replication-deficient adenoviral genes. The final ade- 


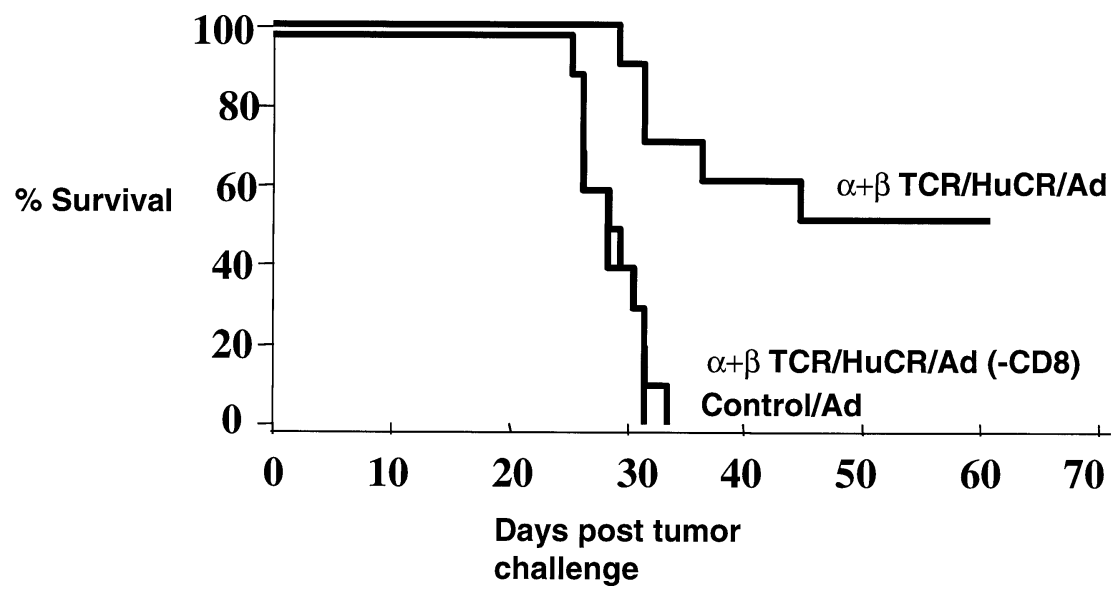

FIGURE 4. Tumor protection is dependent on $\mathrm{CD} 8^{+}$cells. (Reprinted by permission from Wong \& Levy. ${ }^{3}$ )

novirus vaccine required about four weeks to produce (FIG. 2). ${ }^{3}$ We were then able to show specific expression of the TCR in adenovirus-infected cells. When the C6VL variable regions were coupled with human constant regions, the viral vaccine showed protection against tumor challenge (FIG. 3). ${ }^{3}$ We also showed the generation of a specific antibody response to the tumor-specific TCR-Id and abrogation of protection with CD8 depletion (FIG. 4). ${ }^{3}$ In this model, protection required linkage of the mouse variable regions to human TCR constant regions and was CD8 T cell dependent.

\section{STRATEGIES FOR TCR VACCINATION IN HUMANS}

TCR-Id vaccination in humans becomes a more complicated problem because of the variability of usage of the different TCR $\alpha$ and $\beta$ chains. Previously we have shown that TCR V $\beta$ usage is nonpreferential in MF. ${ }^{37}$ Thus many $\alpha$ and $\beta$ TCR family-specific primers might be needed for cloning of TCR genes from all human MF samples. Although this approach is feasible, there exists an easier method known as RACE (rapid amplification of cDNA ends). ${ }^{38-40}$ This method involves reverse transcribing the TCR genes using constant region primers and creating a homopolymeric tail on the $5^{\prime}$ end so as to avoid usage of multiple family-specific primers for PCR amplification. A further modification of this technique known as SMART PCR (developed and marketed by Clontech Laboratories) ${ }^{41}$ is now being used in our laboratory for cloning of whole TCR $\alpha$ and $\beta$ variable regions. ${ }^{42-44}$ This method also adds a consensus primer to the $5^{\prime}$ end of the cDNA. In addition it takes advantage of the touchdown PCR strategy. ${ }^{45}$

In our hands, this method yields complete $\alpha$ and $\beta$ variable regions with fewer cycles of PCR compared to traditional RACE, when performed on MF samples. We are able to obtain monoclonal bands and then, by sequencing, identify our unique 


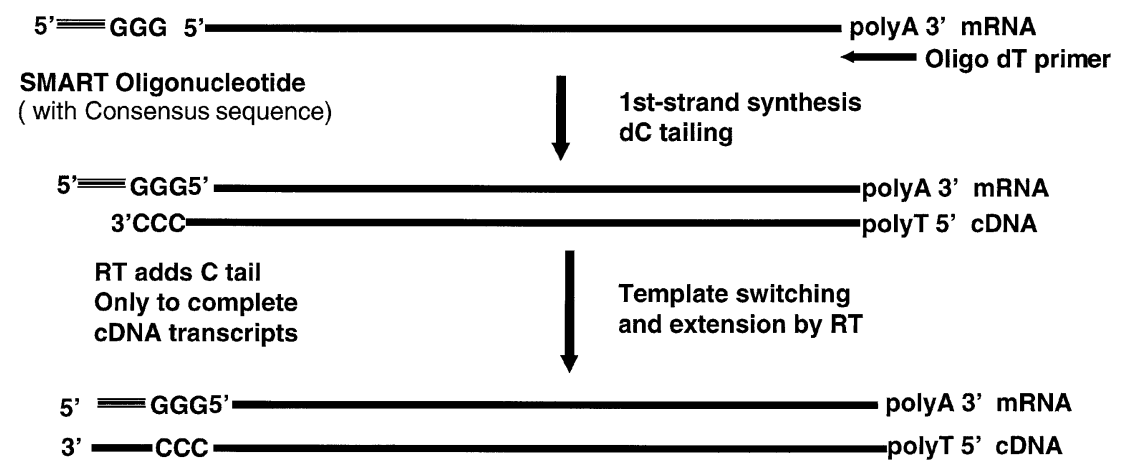

FIGURE 5. Smart PCR cDNA synthesis. The RT reaction contains both the smart primer and an oligo dT primer along with total mRNA.

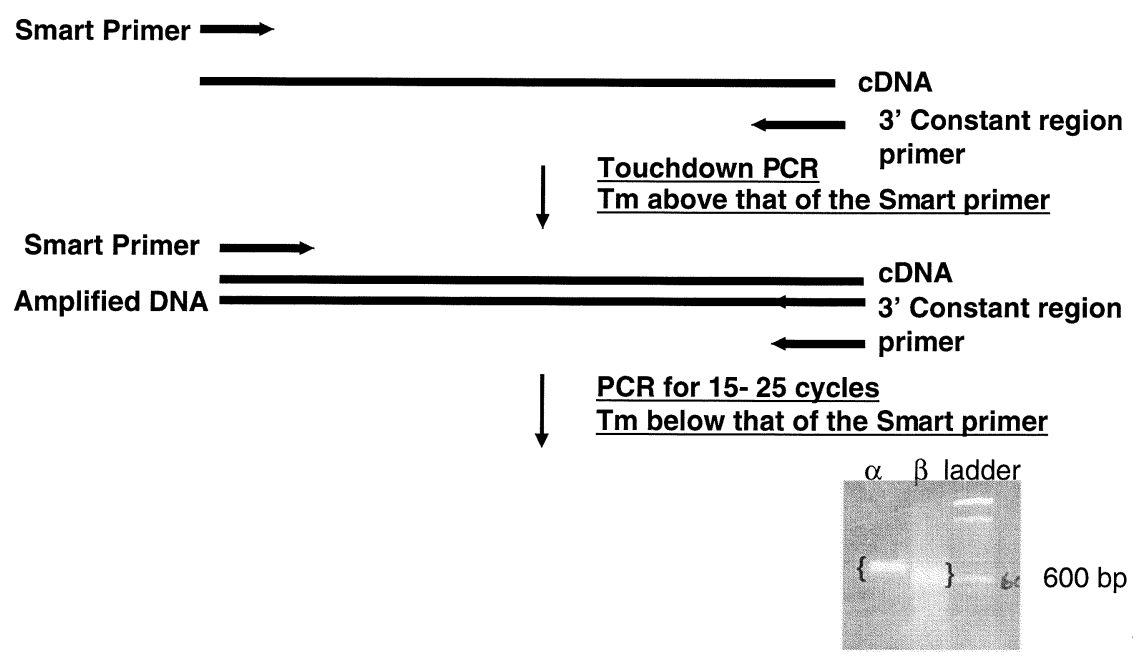

FIGURE 6. Smart PCR. Cloning and sequencing of PCR band.

clonal receptor. This methodology is thus validated for the purpose of cloning TCRs from tumor populations (FIGS. 5-8).

Our current plans involve use of a TCR-Id vaccine in MF patients. This phase I/ II study will assess safety and feasibility. In addition, we will measure patient sera for evidence of a TCR-Id-specific immune response. Based on the mouse model we plan to use xenogeneic (mouse) constant regions coupled to human TCR variable regions for the vaccines.

Important questions remain with regard to the specific details of this trial. One of the most crucial issues is to determine the best vector for delivery of a TCR vaccine. Would adjuvant be required in humans with the use of a xenogeneic (mouse) con- 


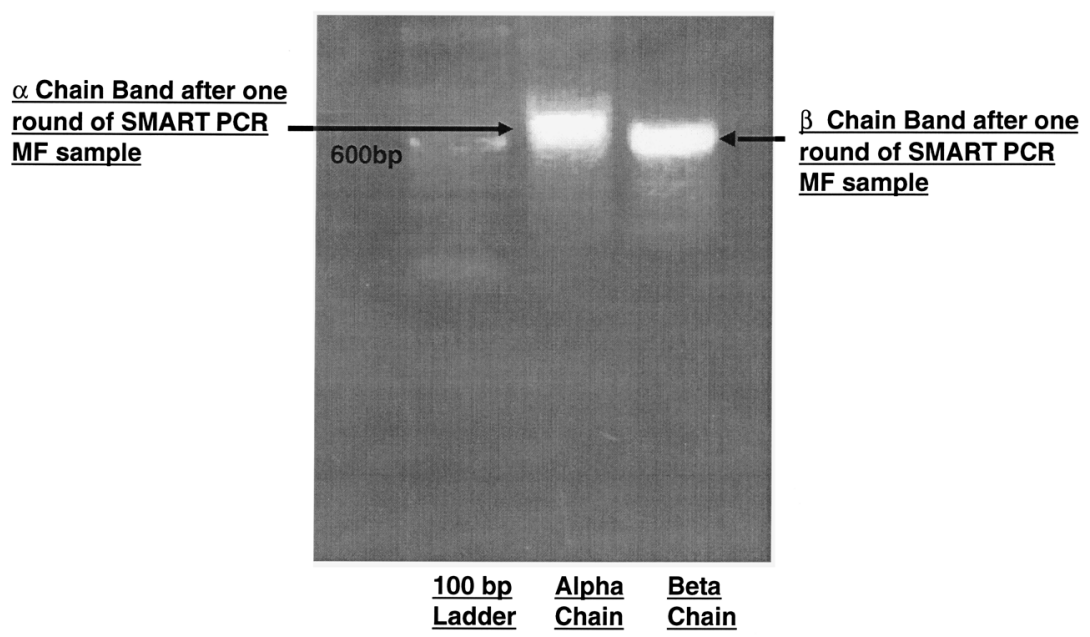

FIGURE 7. Smart PCR gel.

$\alpha$ VARIABLE REGION 5 , T0 3

WTH CDR3 REGION AND CONSENSUS FLANKING SEQUENCES

CLONE ATG TGTGCA

86006 ATG TGTGCT

86003 ATG TGTGCT

86025 ATC

86016 ATC

86020 ATC

86009 ATC

TGTGCT

TGTGTT

TGTGCA
GCAAGCAGATCTAATAATGCAGGCAACATGCTCACC

CTGACCTTTTCTGGGGCTGGGAGTTACCAACTCACT TATAGGAGCTIAAATACCGGCACTGCCAGTAAACTCC TMGGGGGGGGTATGOGCAGAATTTGC CTGAGTGATCAMGGCAACACAGGCAAACTAATC GAGGTCGGGTACAATAACAATGACATC GTGAACGGTGGCCAGAAGCTGCTC

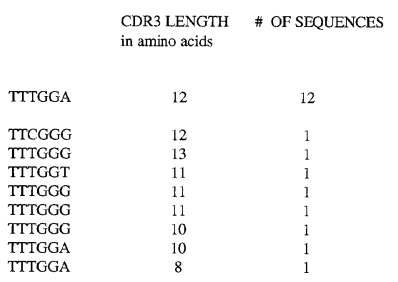

FIGURE 8. Representative alpha-chain sequence showing 12 out of 20 clones with identical sequence.

stant region? What patient populations of MF would be most suitable for pilot studies? Should they receive standard treatment followed by vaccine, or upfront vaccine therapy?

\section{ACKNOWLEDGMENT}

S. A. Reddy is a Cure for Lymphoma Foundation Scholar.

\section{REFERENCES}

1. Okada, C.Y., C.P. Wong, D.W. Denney \& R. Levy. 1997. TCR vaccines for active immunotherapy of $T$ cell malignancies. J. Immunol. 159: 5516-5527.

2. Wong, C.P., C.Y. OKADA \& R. Levy. 1999. TCR vaccines against T cell lymphoma: QS-21 and IL-12 adjuvants induce a protective $\mathrm{CD} 8^{+} \mathrm{T}$ cell response. J. Immunol. 162: $2251-2258$. 
3. Wong, C.P. \& R. Levy. 2000. Recombinant adenovirus vaccine encoding a chimeric Tcell antigen receptor induces protective immunity against a T-cell lymphoma. Cancer Res. 60: 2689-2695.

4. EdELSON, R.L. 1998. Cutaneous T-cell lymphoma: a model for selective immunotherapy. Cancer J. Sci. Am. 4: 62-71.

5. GirARDi, M. \& R.L. Edelson. 2000. Cutaneous T-cell lymphoma: pathogenesis and treatment [in process citation]. Oncology (Huntingt.) 14: 1061-1070; discussion 1070-1074, 1076.

6. KIM, Y.H. \& R.T. Hoppe. 1999. Mycosis fungoides and the Sezary syndrome. Semin. Oncol. 26: 276-289.

7. Siegel, R.S., T. Pandolfino, J. Guitart, et al. 2000. Primary cutaneous T-cell lymphoma: review and current concepts. J. Clin. Oncol. 18: 2908-2925.

8. Abbas, A.K., A.H. Lichtman \& J.S. Pober. 2000. Cellular and Molecular Immunology, 4th Edition. W.B. Saunders. Philadelphia.

9. George, A.J., S.G. Folkard, T.J. Hamblin \& F.K. Stevenson. 1988. Idiotypic vaccination as a treatment for a B cell lymphoma. J. Immunol. 141: 2168-2174.

10. Campbell, M.J., L. Esserman, N.E. Byars, et al. 1990. Idiotype vaccination against murine B cell lymphoma. Humoral and cellular requirements for the full expression of antitumor immunity. J. Immunol. 145: 1029-1036.

11. Campbell, M.J., W. Carroll, S. Kon, et al. 1987. Idiotype vaccination against murine B cell lymphoma. Humoral and cellular responses elicited by tumor-derived immunoglobulin $\mathrm{M}$ and its molecular subunits. J. Immunol. 139: 2825-2833.

12. Hsu, F.J., C.B. CASPaR, D. Czerwinski, et al. 1997. Tumor-specific idiotype vaccines in the treatment of patients with B-cell lymphoma-long-term results of a clinical trial. Blood 89: 3129-3135.

13. Hsu, F.J., C. BeniKe, F. FAGNONI, et al. 1996. Vaccination of patients with B-cell lymphoma using autologous antigen-pulsed dendritic cells. Nat. Med. 2: 52-58.

14. Osterroth, F., A. Garbe, P. Fisch \& H. Veelken. 2000. Stimulation of cytotoxic T cells against idiotype immunoglobulin of malignant lymphoma with protein-pulsed or idiotype-transduced dendritic cells. Blood 95: 1342-1349.

15. SteVenson, F.K. \& J. GoRDON. 1983. Immunization with idiotypic immunoglobulin protects against development of B lymphocytic leukemia, but emerging tumor cells can evade antibody attack by modulation. J. Immunol. 130: 970-973.

16. Stevenson, F.K., D. Zhu, C.A. King, et al. 1995. Idiotypic DNA vaccines against Bcell lymphoma. Immunol. Rev. 145: 211-228.

17. ReichardT, V.L., C.Y. OKada, K.E. StockerL-Goldstein, et al. 1997. Rationale for adjuvant idiotypic vaccination after high-dose therapy for multiple myeloma. Biol. Blood Marrow Transplant. 3: 157-163.

18. Reichardt, V.L., C.Y. OKadA, A. Liso, et al. 1999. Idiotype vaccination using dendritic cells after autologous peripheral blood stem cell transplantation for multiple myeloma-a feasibility study. Blood 93: 2411-2419.

19. Аве, A., N. EMI, H. TAJI, et al. 1996. Induction of humoral and cellular anti-idiotypic immunity by intradermal injection of naked DNA encoding a human variable region gene sequence of an immunoglobulin heavy chain in a B cell malignancy. Gene Ther. 3: $988-993$.

20. CAmpbell, M.J., L. Esserman \& R. LeVy. 1988. Immunotherapy of established murine B cell lymphoma. Combination of idiotype immunization and cyclophosphamide. J. Immunol. 141: 3227-3233.

21. Campbell, M.J., L. Esserman \& N.E. Byars, et al. 1989. Development of a new therapeutic approach to B cell malignancy. The induction of immunity by the host against cell surface receptor on the tumor. Int. Rev. Immunol. 4: 251-270.

22. Caspar, C.B., S. Levy \& R. Levy. 1997. Idiotype vaccines for non-Hodgkin's lymphoma induce polyclonal immune responses that cover mutated tumor idiotypes: comparison of different vaccine formulations. Blood 90: 3699-3706.

23. Miller, R.A., D.G. Maloney, R. Warnke \& R. Levy. 1982. Treatment of B-cell lymphoma with monoclonal anti-idiotype antibody. N. Engl. J. Med. 306: 517-522.

24. BARTH, R.K., B.S. KIM, N.C. LAN, et al. 1985. The murine T-cell receptor uses a limited repertoire of expressed V beta gene segments. Nature 316: 517-523. 
25. Ashwell, J.D., D.L. Longo \& S.H. BRIDGes. 1987. T-cell tumor elimination as a result of T-cell receptor-mediated activation. Science 237: 61-64.

26. Urban, J.L., V. Kumar, D.H. Kono, et al. 1988. Restricted use of T cell receptor V genes in murine autoimmune encephalomyelitis raises possibilities for antibody therapy [see comments]. Cell 54: 577-592.

27. Acha-Orbea, H., D.J. Mitchell, L. Timmermann, et al. 1988. Limited heterogeneity of $\mathrm{T}$ cell receptors from lymphocytes mediating autoimmune encephalomyelitis allows specific immune intervention. Cell 54: 263-273.

28. Owhashi, M. \& E. Heber-Katz. 1988. Protection from experimental allergic encephalomyelitis conferred by a monoclonal antibody directed against a shared idiotype on rat T cell receptors specific for myelin basic protein. J. Exp. Med. 168: 2153-2164.

29. Hashim, G.A., A.A. Vandenbark, A.B. Galang, et al. 1990. Antibodies specific for VB8 receptor peptide suppress experimental autoimmune encephalomyelitis. J. Immunol. 144: 4621-4627.

30. Offner, H., G.A. Hashim \& A.A. Vandenbark. 1991. T cell receptor peptide therapy triggers autoregulation of experimental encephalomyelitis. Science 251: 430-432.

31. Howell, M.D., S.T. WinTERS, T. OleE, et al. 1989. Vaccination against experimental allergic encephalomyelitis with $\mathrm{T}$ cell receptor peptides [published erratum appears in Science 1990 Mar 9; 247 (4947): 1167]. Science 246: 668-670.

32. VAndenbark, A.A., G. Hashim \& H. OfFner. 1989. Immunization with a synthetic Tcell receptor V-region peptide protects against experimental autoimmune encephalomyelitis. Nature 341: 541-544.

33. Chunduru, S.K., R.M. Sutherland, G.A. Stewart, et al. 1996. Exploitation of the Vbeta8.2 $\mathrm{T}$ cell receptor in protection against experimental autoimmune encephalomyelitis using a live vaccinia virus vector. J. Immunol. 156: 4940-4945.

34. KANAGAWA, O. 1989. In vivo T cell tumor therapy with monoclonal antibody directed to the $\mathrm{V}$ beta chain of $\mathrm{T}$ cell antigen receptor. J. Exp. Med. 170: 1513-1519.

35. Janson, C.H., M.J. Tehrani, H. Mellstedt \& H. Wigzell. 1989. Anti-idiotypic monoclonal antibody to a T-cell chronic lymphatic leukemia. Characterization of the antibody, in vitro effector functions and results of therapy. Cancer Immunol. Immunother. 28: $225-232$.

36. Lin, A.Y., B. Devaux, A. Green, et al. 1990. Expression of T cell antigen receptor heterodimers in a lipid-linked form. Science 249: 677-679.

37. BAhler, D.W., G. BerRy, J. OKSENBerg, et al. 1992. Diversity of T-cell antigen receptor variable genes used by mycosis fungoides cells. Am. J. Pathol. 140: 1-8.

38. Ferradini, L., S. Roman-Roman, O. Azogui, et al. 1993. The use of anchored polymerase chain reaction for the study of large numbers of human T-cell receptor transcripts. Mol. Immunol. 30: 1143-1150.

39. Osterroth, F., O. Alkan, A. Mackensen, et al. 1999. Rapid expression cloning of human immunoglobulin Fab fragments for the analysis of antigen specificity of B cell lymphomas and anti-idiotype lymphoma vaccination. J. Immunol. Methods 229: $141-153$.

40. Loh, E.Y., J.F. ElliotT, S. CwIRla, et al. 1989. Polymerase chain reaction with singlesided specificity: analysis of T cell receptor delta chain. Science 243: 217-220.

41. Smart Race cDNA Amplification Kit User Manual. 1999. Clontech Laboratories. Palo Alto, CA.

42. Chenchik, A., L. Diachenko, F. Moqadam, et al. 1996. Full-length cDNA cloning and determination of mRNA $5^{\prime}$ and $3^{\prime}$ ends by amplification of adaptor-ligated cDNA. Biotechniques 21: 526-534.

43. Matz, M., D. Shagin, E. Bogdanova, et al. 1999. Amplification of cDNA ends based on template-switching effect and step-out PCR. Nucleic Acids Res. 27: 1558-1560.

44. KellogG, D.E., I. Rybalkin, S. Chen, et al. 1994. TaqStart Antibody: "hot start" PCR facilitated by a neutralizing monoclonal antibody directed against Taq DNA polymerase. Biotechniques 16: 1134-1137.

45. Don, R.H., P.T. Cox, B.J. WAINwright, et al. 1991. 'Touchdown' PCR to circumvent spurious priming during gene amplification. Nucleic Acids Res. 19: 4008. 